Daimon. Revista Internacional de Filosofía, $\mathrm{n}^{\circ}$ 83, 2021 pp. 171-184

ISSN: 1130-0507 (papel) y 1989-4651 (electrónico)

http://dx.doi.org/10.6018/daimon.372371

Las obras se publican en la edición electrónica de la revista bajo una licencia Creative Commons ReconocimientoNoComercial-SinObraDerivada 3.0 España (texto legal). Se pueden copiar, usar, difundir, transmitir y exponer públicamente, siempre que: i) se cite la autoría y la fuente original de su publicación (revista, editorial y URL de la obra); ii) no se usen para fines comerciales; iii) se mencione la existencia y especificaciones de esta licencia de uso.

\title{
La historiografía apologética en el Discurso Contra los griegos de Taciano el Sirio
}

\section{The apologetic historiography in the Discourse Against the Greeks of Tatian the Syrian}

Resumen: En este trabajo nos proponemos poner de manifiesto un aspecto poco estudiado del Contra los griegos de Taciano (circa 170); nos referimos a la introducción del discurso historiográfico en la apologética cristiana. En cumplimiento de nuestro objetivo daremos cuenta, por una parte, del carácter idiosincrático de la producción de este apologista en el contexto de la defensa de la fe cristiana en el s. II y analizaremos, por otra, lo que de acuerdo con nuestra línea de investigación es lo más relevante de su controvertido modus cogitandi: el rechazo de la Filosofía como via regia de acceso al Cristianismo para las gentes de alta cultura y la introducción del discurso historiográfico como garantía de veracidad.

Palabras clave: apologética cristiana, historiografía, filosofía, Taciano, Discurso contra los griegos.

\begin{abstract}
In this paper I propose to highlight a little studied aspect of the Discourse Against the Greeks of Tatian (circa 170); we refer to the introduction of historiographical discourse in Christian apologetics. In fulfillment of our objective we will give account, on the one hand, of the idiosyncratic character of the production of this apologist in the context of the defense of the Christian faith in the s. II and we will analyze, on the other hand, what according to our line of research is the most relevant of his controversial modus cogitandi: the rejection of Philosophy as a way of access to Christianity for people of high culture and the introduction of the historiographical discourse as a guarantee of truthfulness.
\end{abstract}

Keywords: Christian apologetics, historiography, philosophy, Tatian, Discourse Against the Greeks.

\section{La importancia de Taciano como apologista}

Hacia el final del Discurso contra los griegos (П○ó $\bar{\varepsilon} \lambda \lambda \eta v \alpha \varsigma),{ }^{1}$ dispuesto a resumir el contenido de su tratado en unas pocas líneas, Taciano escribió:

Recibido: 17/04/2019. Aceptado: 25/03/2020.

* Profesor, Licenciado y Doctor en Filosofía por la Universidad de Buenos Aires (UBA) y becario postdoctoral del Consejo de Investigaciones Científicas y Tecnicas (CONICET). Se desempeña como investigador en la Universidad de Buenos Aires en las áreas de Lengua y Cultura Latinas y Filosofía Tardoantigua, Medieval y Renacentista en la Sección de Estudios de Filosofía Medieval.

1 Más que por su título original en griego, el Discurso de Taciano es conocido por un título latino: Oratio ad graecos. De aquí en más, tanto en el cuerpo del texto como en las notas al pie nos referiremos a esta obra como "Discurso". 


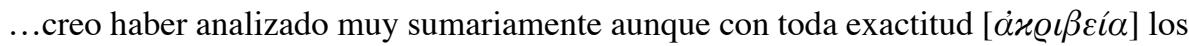

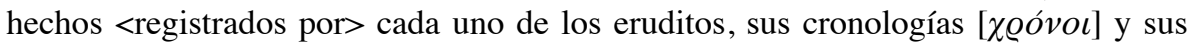

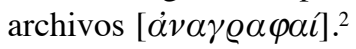

No es casual que el apologista haya elegido estos términos al finalizar, ${ }^{3}$ toda vez que su

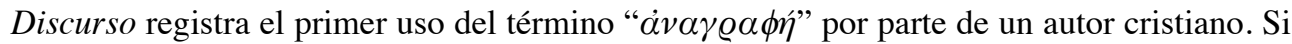
bien en dicho pasaje hemos vertido esta voz, en plural, por "archivos", podríamos haberla traducido también por "registros", "anales" o "cronología documental", es decir, "cronología basada en textos, en registros". Sea de ello lo que fuere, no nos importa solo el hecho de que Taciano haya introducido esta palabra en un contexto nuevo, antes bien, el haberla introducido es síntoma del rigor metodológico, i.e., $\alpha \varkappa \varrho \iota \beta \varepsilon \iota ́ \alpha$, que imprimió en el estudio de la historia, en suma, su rigor o exactitud historiográfica. ${ }^{4} \mathrm{Si}$ Taciano se esforzó por ser exacto, es porque estaba convencido de que

...a quienes poseen un archivo [ $\alpha \dot{v} \alpha \gamma \varrho \alpha \varphi \eta ́]$ desordenado les es imposible verificar

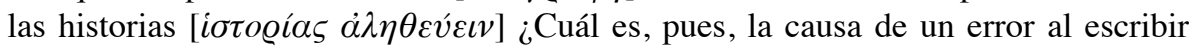
- remata - sino utilizar datos que no son verdaderos ${ }^{5}$

Lo que parece proponer Taciano en su Discurso es, para decirlo con pocas palabras, una verdad histórica que solo el estudio atento y ordenado puede alcanzar. ${ }^{6}$ El Discurso, en efecto, redactado hacia el 170, en pleno reinado de Marco Aurelio (161-180), diversifica el género apologético introduciendo en este la historiografía. ${ }^{7}$

Taciano el Sirio es el tercer apologista del s. II, en orden cronológico, después de Arístides y Justino Mártir, cuya obra ha llegado hasta nosotros. A pesar de ser un discípulo directo del célebre Justino, quizás el más profundo de los apologistas de ese siglo, el pensamiento de Taciano tiene un ritmo muy distinto del de su maestro: si aquél presentaba la filosofía griega como una praeparatio evangelica, éste la rechaza de plano transformándola, como veremos, en una degradatio mosaica y contraponiéndole lo que él llama la "filosofía bárbara". Pero hay más: por "filosofía", sin más, el autor del Discurso entiende todo aquello que, en sentido amplio, los griegos tomaron por sabiduría, esto es, la literatura filosófica en sentido estricto, las obras de los grandes dramaturgos, tanto la tragedia como la comedia, la gramática, entendida como una ciencia de las letras y la argumentación, es decir, como un híbrido entre retórica y gramática, y la mitología, tomada como una suerte de teología

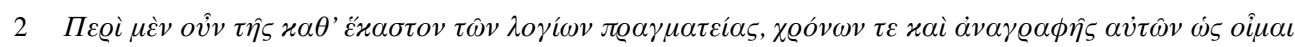

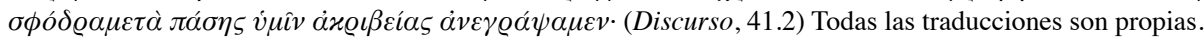

3 I.e., dx

4 Cf. Martín, J. P. (2013), «La historiografía como género apologético en los orígenes cristianos», en Alesso, M. (ed.): Hermenéutica de los Géneros Literarios: de la Antigüedad al Cristianismo: Buenos Aires, Editorial de la Facultad de Filosofía y Letras (UBA), pp. 71-77.

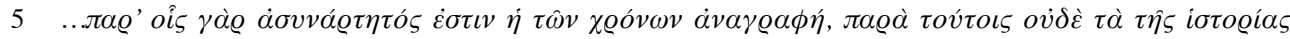

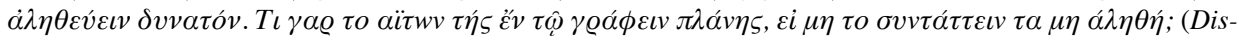
curso, 31,4).

6 Cf. Discurso, 20.2; 31, 1; 35, 1; 36, 1-40, 1. También cf. Elze, M. (1960), Tatian und seine Theologie, Göttingen: Andenhoeck \& Ruphecht., cap. 2 "Tatians Auffassung von der Wahrheit", pp. 34-40.

7 Cf. Pouderon, B. (2005), Les Apologistes grecs du IIe siècle, Paris: Les Éditions du Cerf, pp. 175ss. 


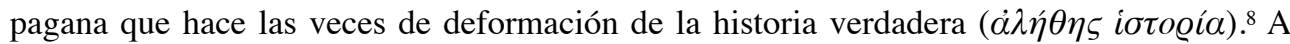
estos elementos que nosotros identificaríamos hoy como componentes no de la filosofía sino de la cultura griega en general, suma Taciano otros dos que estaban llamados a cobrar relevancia en la era del Imperio, a saber, los espectáculos públicos, en especial los combates lúdicos y la legislación romana: filósofos, tragediógrafos y comediógrafos, gramáticos y rétores, mitógrafos, agonotétas y juristas son los autores de la "filosofía" a la que ataca. Son estos, en suma, la causa por la que los griegos vienen considerados en el Discurso "elegantes de palabra pero locos de pensamiento" (o bien, "ingeniosos en cuanto a la expresión pero antinaturales en cuanto al entendimiento"). ${ }^{9}$

\section{El ataque y la defensa de Taciano}

En cuanto a su estructura formal, el Discurso, que parece haber sido escrito para ser leído ante una multitud de griegos, se inicia con una exhortación inquietante que nos da una pista de la argumentación de Taciano:

No os mostréis tan de todo en todo enemigos de los bárbaros [ $\beta \alpha \dot{\varrho} \beta \alpha \varrho o l]$, varones

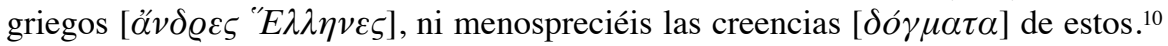

Se definen aquí los términos del agón que comienza: de un lado los griegos, del otro, los bárbaros, i.e., judíos y cristianos. ${ }^{11}$ Así pues, en el Discurso de Taciano se pueden distinguir dos partes no netamente diferenciadas que se van intercalando a medida que se desarrollan los sucesivos argumentos: una pars destruens, en la que ataca todo lo que, por ser griego, considera contrario a la religión cristiana, y una pars construens donde aboga en favor de lo que él llama "filosofía bárbara". ${ }^{12}$

8 Cf. Norelli, E. (1996), «La critique du pluralisme grec dans le Discours aux Grecs de Tatien» en Pouderon, B.Doré, J. (eds.), Les apologistes chrétiens et la culture grecque, Paris: Beauchesne, pp. 89-94.

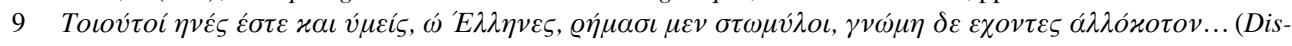
curso, 14.1)

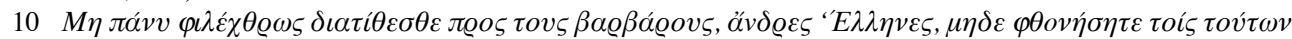
$\delta o ́ \gamma \mu \alpha \sigma \omega \nu$. (Discurso, 1.1)

11 El Discurso está estructurado en cuarenta y dos parágrafos a lo largo de los cuales el autor aborda temas de diverso tenor y complejidad. Lo primero que deberíamos destacar es que, a pesar de ser un texto escrito contra los griegos, para sumarnos a toda una legión de intérpretes, está redactado como si efectivamente se hubiera leído o, cuanto menos, pronunciado ante un auditorio griego. No se trata, en efecto, de un grupo de personas de lengua griega, pues el propio Taciano era un sirio helenizado que se expresaba en esta lengua, sino de un conjunto homogéneo de hombres de cultura griega. Desde ya que hablaban la lengua griega y la utilizarían para la comunicación y para escribir, pero nuestro autor se refiere más a bien a gentes que asumen como verdaderos los pilares de la civilización helénica, i.e., su filosofía, literatura, retórica, y después de un largo etcétera, su historia. Desde el comienzo del Discurso queda claro que Taciano se propone confrontar a los griegos y su cultura con la "cultura bárbara", i.e., la de quienes no hablaban la lengua griega, la de los judíos y los primeros cristianos.

12 Una legión de eruditos soporta la distinción convencional de la apologética cristiana en dos etapas, una que incluye todos los autores anteriores a la conversión de Constantino definida como apologia pro christianis y otra, post-constantiniana, como una categoria contra gentes. La obra de Taciano no cuadra exactamente con esta división, pues incluye toda una serie de elementos que son característicos del segundo período de la apologética, entre ellos, críticas y descalificaciones a la cultura pagana; Taciano no las incluye a modo de datos de 


\subsection{Pars destruens}

Después de presentar los términos de la discusión, Taciano hace un sesgado recuento de las invenciones de variadas culturas que los griegos antiguos adoptaron como propias y que los griegos contemporáneos tienen por tales, sin cuestionamiento alguno. ${ }^{13}$ El objetivo del apologista es mostrar, por medio de una referencia a las instituciones y disciplinas consagradas de los griegos, que éstas tuvieron origen entre los bárbaros, término con el que, en el comienzo del Discurso señala a los pueblos extranjeros, en general, pero que con el correr de su argumentación se va ajustando para designar explícitamente a los judíos y, de manera tácita, a los cristianos. Los griegos, en suma, no inventaron nada, se limitaron sólo a imitar a los bárbaros. En su crítica múltiple, como veremos enseguida, emerge la idea unánimemente aceptada en su época, de que lo más antiguo es lo mejor y lo verdadero. ${ }^{14}$

\subsubsection{Crítica a los filósofos}

De acuerdo con Taciano, en la filosofía griega no hay nada que merezca respeto. ${ }^{15}$ Así pues, ataca a los filósofos sobre todo por su arrogancia ( $\alpha \lambda \alpha \zeta o v \varepsilon i ́ \alpha)$, presentando argumentos ad hominem uno tras otro basados en anécdotas de dudosa procedencia. A lo largo de su crítica se empeña contra Diógenes el Cínico, Aristipo, Platón, Aristóteles, Heráclito, Zenón, Empédocles, Ferécides, Pitágoras y Crates. ${ }^{16}$ No vale la pena que nos detengamos en cada una de las conclusiones del apologista; el único concepto digno de nuestra atención que cae

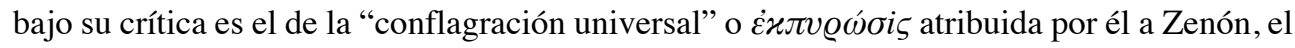
fundador del estoicismo. Lo que sí hay que destacar es que Taciano parece tener una concepción de la filosofía como un continuum, valga la redundancia, sin solución de continuidad:

...los choques entre ellos <los filósofos $>$ son muchos, pues el uno aborrece al otro sentando doctrinas opuestas por pura fanfarronería $[\dot{\alpha} \lambda \alpha \zeta o v \varepsilon i ́ \alpha]$, aspirando a puestos eminentes..$^{17}$

color sino como parte estructural de su Discurso. Por esto, algunos estudiosos de su obra han estipulado que el género literario del texto no es apologético sino protréptico o arenga. Para más detalles nos remitimos a Quasten, J. (1954), Patrología I, Madrid: BAC, p. 213 y McGehee, M., (1993), «Why Tatian never "Apologyzed” to the Greeks», Journal of early Christian Studies, ${ }^{\circ}$ 1, pp. 143-155.

13 El recuento de artes y disciplinas con sus inventores que Taciano hace en la sección introductoria del Discurso revela inmediatamente un conocimiento exhaustivo de la cultura griega, al menos en sus rasgos generales más superficiales: atribuye la adivinación por medio de sueño a los telmisios, la astrología a los carios, los auspicios a isaurios y frigios, el arte de sacrificar a los ciprios, la astronomía a los babilonios, la magia a los persas, la geometría a los egipcios, las letras a los fenicios, el arte de la flauta y la siringa a los mitológicos Marsias y Olimpo, el de la trompeta a los tirrenos, y la técnica para labrar metales a los cíclopes. Se trata de un recuento arbitrario en el que deliberadamente no se distinguen las fuentes históricas de las mitológicas. (Cf. Discurso, 1)

14 Cf. Discurso, 1-27 et passim.

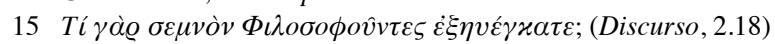

16 Cf. Discurso, 2-3 y 25.

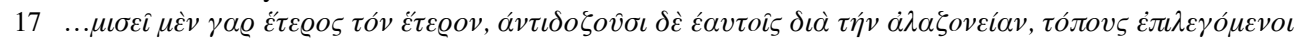

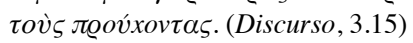


Se trata de una concepción de la Filosofía que se volverá a ver en el Escarnio de los filósofos paganos, de Hermias el Filósofo, el último de los apologistas griegos del s. II. Por lo demás, es evidente que Taciano juzga a todos los filósofos a partir de una noción de la filosofía que era corriente su época, i.e., la de la filosofía helenística tardía y de los autores que se inscriben en la Segunda Sofística. ${ }^{18}$ En efecto, el ideal de todas las escuelas originales del período, estoicismo, epicureísmo, escepticismo y cinismo, no es otro que la autosuficiencia ( $\alpha \dot{v} \tau \alpha \varrho x \varepsilon ́ \iota \alpha)$, aunque en su aplicación adquiera matices diferentes; se ha de tener en cuenta que, además, cuando se refiere a los filósofos pre-helenísticos, Platón, Aristóteles, Ferécides, Pitágoras, etc. Taciano nos habla de sus seguidores o de sus doctrinas no de ellos mismos. ${ }^{19}$ Así, la acusación de arrogancia a los filósofos se justifica, según él, en que dicen no necesitar de nada ni de nadie cuando en realidad necesitan de un tejedor para el manto, de un leñador para el bastón, etc. la semblanza estereotipada que hace el apologista de la figura del filósofo tiene un sorprendente parecido con la del sofista Hippias tal como lo pinta Platón en el diálogo homónimo. ${ }^{20}$ Más allá de este detalle, la crítica a los filósofos paganos se cierra con una serie de oposiciones: para los paganos Dios es cuerpo, para los cristianos incorpóreo; para los primeros el mundo es indestructible y para los segundos, destructible; para los filósofos la conflagración universal ocurre de manera cíclica, para los cristianos una sola vez; para los paganos los jueces son Minos y Radamante, para los cristianos es Dios mismo; para los paganos el alma es inmortal, para los cristianos también lo es el cuerpo en ella, etc. ${ }^{21}$

\subsubsection{Contra el teatro}

El teatro, de acuerdo con Taciano, enseña a mentir y conduce a los hombres al deshonor. En su peroración contra el teatro confiesa haber sido afectado por las representaciones, en especial por los actores:

...yo vi muchas veces a uno, y habiéndolo visto, me maravillé, y después de maravillarme, lo desprecié porque era uno por dentro y otro por fuera, y mentía lo que no era, en extremo afeminado y disoluto; unas veces relampagueaban sus ojos, otras gesticulaba ágilmente con las manos: ora hacía el loco con su máscara de barro, se convertía en Afrodita o Apolo...22

18 Cf. Nasrallah, L. (2005), «Mapping the World: Justin, Tatian, Lucian, and the Second Sophistic.», Harvard Theological Review, $\mathrm{n}^{\circ}$ 98-3, pp. 289-293.

19 No se nos escapa que Taciano tuvo conocimiento del platonismo medio. Con todo, el blanco de ataque preferencial no son los platónicos sino los estoicos. Para más detalles sobre este punto cf. Hunt, E. J. (2003), Christianity in the Second Century. The case of Tatian, London-New York: Routledge, cap. 4 "Tatian and Hellenistic philosophy", pp. 74-109.

20 Cf. Platón, Hippias Menor, 368b-369a.

21 Cf. Discurso, 25.1-3.

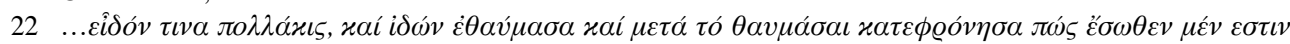

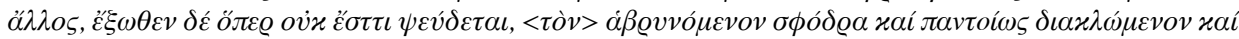

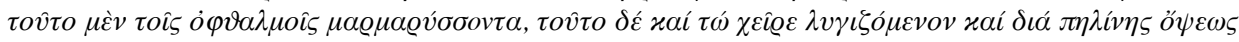

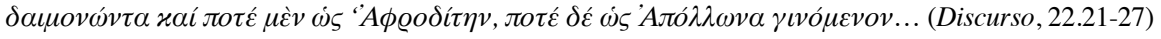


El actor es, en suma, mentiroso en todo ( $\pi \alpha ́ v \tau \alpha \psi \varepsilon v \delta o ́ \mu \varepsilon v o \varsigma),{ }^{23}$ así como también los dramaturgos (oï $\pi \circ \imath \eta \tau \alpha \grave{\text { ) }}$. A juicio del apologista, los griegos se desviven por el teatro, ultrajando al mismo tiempo a los que no toman parte en los entretenimientos públicos. Y denuncia, como gritando, que por medio de estos espectáculos se les da a los niños lecciones acerca de cómo cometer adulterio, ${ }^{24}$ para presentar, finalmente, enérgicas muestras de su inutilidad a través de obras de Eurípides y de Hegesipo y Menandro. ${ }^{25}$

\subsubsection{Contra los espectáculos de gladiadores}

Otro de los espectáculos públicos que Taciano rechaza es la lucha de gladiadores. En este punto su lenguaje es más áspero aun que en el caso anterior: es inmoral en sí y no conlleva ninguna virtud, sentencia. Pero eso no es todo: este tipo de juegos - sigue, dirigiendo la crítica a los agonotetas - llega a tal extremo que el pobre se vende a sí mismo para participar mientras el rico compra a aquellos que habrán de matarlo. Eso en cuanto a los preparativos, en cuanto a la lucha en sí, tampoco hay algo digno de ser visto: dos o más hombres combaten sin objetivo alguno, más que la cruenta diversión de gentes sin escrúpulos. Como extrañado, hacia el final Taciano se dirige a los griegos que, supuestamente están escuchando para preguntarles si éstas son las buenas acciones que practican, es decir, la de tratar a los hombres como animales. ${ }^{26}$ En este, como en todos los ataques, la retórica del apologista termina en una ridiculización de los "griegos" que a esta altura no son griegos sino "paganos vistos por un cristiano".

\subsubsection{Contra la multiplicidad de leyes}

Taciano critica también las leyes porque, de acuerdo con su punto de vista (el cual asume la idea de una gran comunidad de seres humanos que, aunque viviendo en diferentes partes del globo, practican una misma religión), debería haber una sola constitución política para todos ( en sentido estricto, sino un asunto de costumbres: las leyes, afirma, varían de ciudad en ciudad de modo tal que lo que para unos es vergonzoso, para otros, honroso. ${ }^{27}$ Los ejemplos que aduce, acerca del incesto y la pederastia, están basados en una falta absoluta de conciencia respecto de lo que hoy se conoce como "relativismo cultural". Lo único que le interesa enfatizar es que estas costumbres chocan de lleno con la moral cristiana. Se percibe, pues, que utiliza el término griego "vó $\mu o \varsigma$ " a discreción; éste, como es sabido, tiene el doble sentido de ley y costumbre. Pero el problema de fondo no es un asunto de relativismo cultural ni mucho menos, sino algo más simple e inmediato, a saber, que las costumbres de los paganos no son consistentes con las de los cristianos:

\footnotetext{
23 Discurso, 22.4.

24 Cf. Discurso, 22.10-11.

25 Cf. Discurso, 24.

26 Cf. Discurso, 23.

27 Cf. Discurso, 28.
} 
Si yo no quiero someterme a las leyes de ciertas gentes ¿por qué he de ser aborrecido

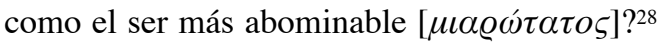

Por lo demás, se declara fiel y obediente al emperador en todo, solo en una cosa no está dispuesto a obedecer: si se le ordena negar a Dios. ${ }^{29}$

\subsubsection{Contra los gramáticos}

En su ataque contra los gramáticos, Taciano los culpa de haber sido el origen de toda la, en su opinión, despreciable cultura griega: "el principio de vuestra charlatanería fueron los gramáticos", ${ }^{30}$ les echa en cara a los griegos. Y, sigue, y ahora parece gritarles no a los gramáticos sino a los filósofos: ${ }^{31}$ “...os apropiáis de las palabras, sí, pero luego habláis como un ciego con un sordo." ${ }^{32}$ Acusa también a los gramáticos de abusar de las figuras retóricas. En suma, "las contradicciones de sus libros se parecen a un laberinto." 33

\subsubsection{Contra la mitología}

En el ataque contra la mitología, por último, Taciano se encara contra un híbrido de teología pagana e historia. En una verdadera vorágine argumental, arma demostraciones contra todos los dioses principales de los griegos al tiempo que ataca las instituciones que rigen sus cultos respectivos. La clave fundamental del ataque a la mitología es el antropomorfismo de los dioses; todos ellos tienen, para decirlo con pocas palabras, las mismas pasiones que los hombres. En el punto más álgido de la pars destruens, Taciano parece atribuir a los dioses griegos las características de los demonios de la teología judeocristiana, ${ }^{34}$ para, avanzando en su argumentación, acusarlos de ser causa de todas las enfermedades y posesiones.

Párrafo aparte merece una última consideración acerca de la múltiple utilización que hace Taciano del término " $\beta \alpha ́ \varrho \beta \alpha \varrho o \iota "$. Si bien ya hemos adelantado que con él se refería a los "extranjeros", y para designar a aquellos que no hablaban la lengua griega, en especial los judíos y cristianos, llega a decir que los propios griegos deber ser considerados

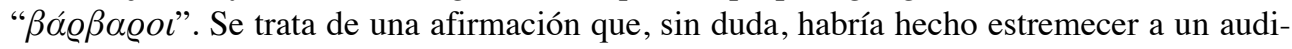
torio de griegos. Con todo, el temerario apologista piensa que este uso del término es lícito toda vez que no se sabe a cuál de los dialectos de la lengua griega (dórico, ático, eólico o jónico) se ha de llamar propiamente "griego". Pero eso no es todo, incluso si fuera posible decidirse por uno de los dialectos, los griegos son culpables de haber dejado entrar voces

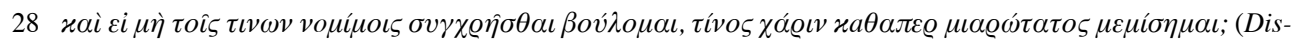
curso, 4.21-23)

29 Cf. Discurso, 4.20-30.

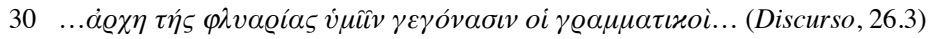

31 En este punto, Taciano menciona la célebre anécdota sobre Tales de Mileto, sin mencionarlo: " $\xi \eta \tau o v v \tau \varepsilon \varsigma \tau i ́ \varsigma$

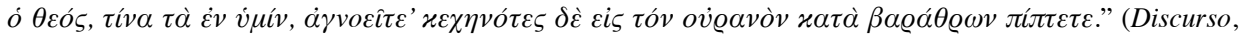
26.19-20)

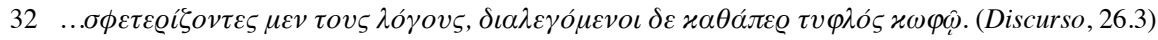

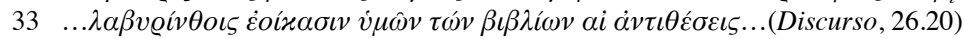

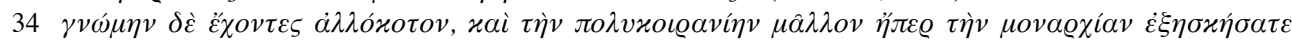

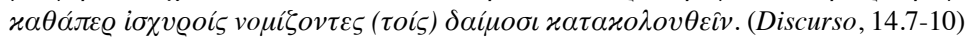


bárbaras ( $\beta \alpha \varrho \beta \alpha \varrho \iota \varkappa \alpha i ́ \Phi \omega v \alpha i$ ) en su lengua, convirtiéndola en un idioma de lo más confuso $(\sigma v \mu \Phi v \varrho \delta \delta \eta v \iota \alpha \lambda \varepsilon \varkappa \tau o ́ \varsigma)$. ${ }^{35}$ En este contexto de descalificación de la lengua griega, cuya consideración hace que los demás pueblos sean considerados bárbaros, Taciano parece atribuir dos invenciones a los griegos como propias de ellos, no imitadas de extranjeros, a saber, la retórica y la poesía; la una para injusticia y calumnia y la otra para la corrupción del alma.

\subsection{Pars construens}

En el momento del Discurso en el que Taciano se propone demostrar la antigüedad y, por tanto, la veracidad de la religión mosaica, esto es, judeocristiana, su argumentación se vuelve más tersa y no hay tantas idas y venidas como en la "pars destruens". El ritmo prosaico del apologista revela un estilo que podríamos calificar de "sofístico": el desorden de la sabiduría griega es algo que se pone de manifiesto a través de su enroscada exposición, el orden y la exactitud de la sabiduría bárbara se pone de manifiesto a través de una exposición lineal. Se pueden distinguir, por cierto, algunos elementos que harán el piso de la pars construens distribuidos aleatoriamente, como enredados, con argumentos de la pars destruens. Tópicos tales como la soledad de Dios, la Creación, la concepción del $\lambda o ́ \gamma o \varsigma$ como $\delta v ́ v \alpha u \iota \varsigma$, la relación entre la divinidad y lo creado en términos platónicos de separación y participación, la resurrección de los cuerpos, el Juicio Final, ${ }^{36}$ la Encarnación, ${ }^{37}$ el libre arbitrio, ${ }^{38}$ el pecado, ${ }^{39}$ la antropología cristiana, ${ }^{40}$ y la justicia divina ${ }^{41}$ Se trata de elementos todos que constituyen una refutación puntual y parcial de algunas concepciones de los paganos. Con todo, para poder organizarlos en un frente de ataque argumental, hay que esperar hasta la pars construens. Así pues, la filosofía bárbara que Taciano se propone defender está representada esencialmente por una correcta interpretación de la historia del mundo porque, insistimos, según él “....a quienes poseen

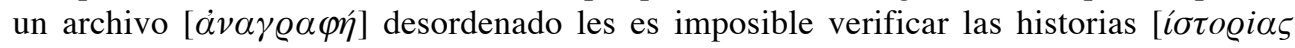
$\alpha ́ \lambda \eta \theta \varepsilon v \varepsilon \varepsilon v] \ldots . .{ }^{42}$ Taciano se presenta como un hombre que busca la verdad. Le conviene, pues, que la entrada a la argumentación a favor de los cristianos adquiera tintes autobiográficos. Así, confiesa haberse topado "casualmente" con unas "escrituras bárbaras", "realmente divinas" más antiguas que las doctrinas de los griegos. Lo que lo llevó a creer en ellas - sigue - es la sencillez de su dicción, la naturalidad de los hombres que en ella hablan, la fácil comprensión de la creación del universo, la previsión de lo futuro, la excelencia de los principios y la unicidad de mando en el universo, ${ }^{43}$ se trata de todas cosas

35 Cf. Discurso, 1

36 Cf. Discurso, 5 y 6.

37 Cf. Discurso, 7.

38 Cf. Discurso, 7, 8 y 9.

39 Cf. Discurso, 11 y 12.

40 Cf. Discurso, 13, 14 y 15.

41 Cf. Discurso, 16-20.

42 Ver nota $n^{\circ} 6$.

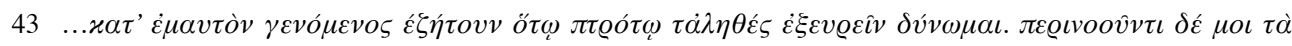

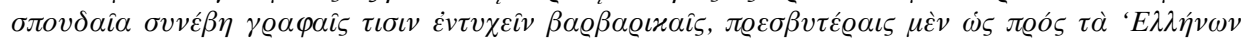

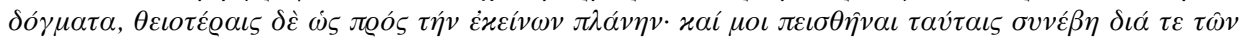

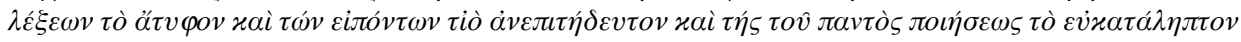


que tienen aplicación inmediata en los múltiples ámbitos del quehacer humano, desde la ética y la política hasta la retórica y la filosofía, sin olvidar, por supuesto, la religión como fuente de seguridad ante las miserias de la época. En este sentido, no se olvida Taciano de enfatizar el aspecto moral de las Escrituras: libran al hombre de la esclavitud del mundo

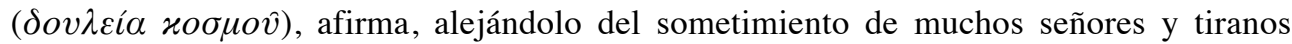
infinitos. Empero, más allá de estas ventajas, la sabiduría bárbara a la que llama ahora "nuestra filosofía" ( $\dot{\eta} \mu \varepsilon \dot{\tau} \varepsilon \varrho \alpha \phi \iota \lambda o \sigma \phi i ́ \alpha)$, es más antigua que las instituciones griegas; ${ }^{44} \mathrm{y}$ se propone demostrarlo. Los límites (ő@o ) de esta demostración serán Moisés y Homero, uno y otro son los autores más antiguos ( $\pi \alpha \lambda \alpha i$ i $\alpha \tau o \iota)$. Homero es el más antiguo de los

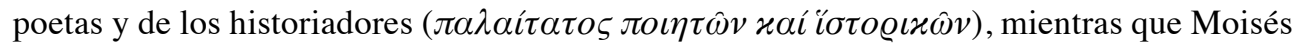

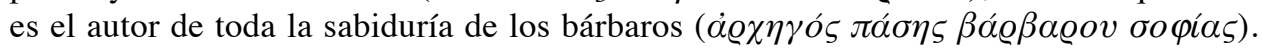

Taciano no anda con medias tintas: se propone demostrar que la religión mosaica, a la que llama una y otra vez "nuestra”, no solo es más antigua que toda la cultura de los griegos sino incluso que la cultura del alfabeto. Pero hay un detalle que oficia como garantía de veracidad: no va a comenzar con testigos de su propia casa, sino de entre los griegos; los combatirá explícitamente con sus propias armas a fin de no caer en argumentos sospechosos.

\subsubsection{Los historiadores griegos}

Taciano afirma que hay tres generaciones de eruditos griegos que se dedicaron a investigar las poesías de Homero, su origen y su floruit..$^{45} \mathrm{Y}$ toma lo dicho por algunos de estos historiadores para dar cuenta de sus contradicciones: según Crates, historiador de la tercera generación, Homero vivió ochenta años después de Troya; según Filócoro de Atenas, de la segunda generación, vivió ciento ochenta años después de Troya; según Apolodoro, otro erudito de la tercera generación, doscientos cuarenta años después; algunos ( $\tau \iota v \dot{\varepsilon} \varsigma$ ), a los que no podemos identificar, afirman - dice Taciano - que cuatrocientos años después de Troya, otros ( $\check{\tau} \tau \varrho o \iota)$, también inidentificables, quinientos años. Las discrepancias se producen porque estos autores, los cuales - recordemos - son todos griegos, no tienen archivos bien ordenados. ${ }^{46}$ En este punto, y más allá de su obvia erudición libresca, Taciano se esfuerza por resaltar, otra vez, el carácter autobiográfico de su argumentación:

...todo esto lo expongo - dice - no porque lo haya yo sabido de otros, sino porque he recorrido y profesé como maestro las doctrinas propias de ustedes < griegos $>$ y he

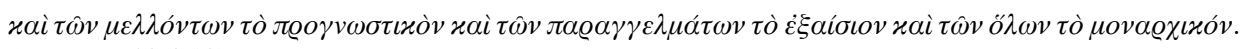
(Discurso, 29.4-12)

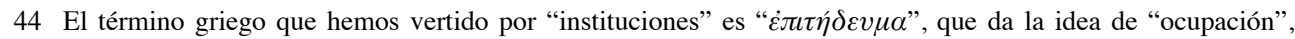
"práctica”, "profesión”, "manera de vivir”, etc. $\dot{\varepsilon} \lambda \lambda \alpha ́ \delta o \varsigma$, i.e., de los griegos.

45 La primera generación está representada por Teágenes de Regio (s. VI), Estesímbroto de Tasos (s. V), Antímaco de Colofón (s. V), Heródoto de Halicarnaso (s. V) y Dionisio de Olinto (V-IV). La segunda, por Éforo de Cima (s. V.IV), Filócoro de Atenas (IV-III), y los peripatéticos Megaclides de Atenas (s. IV-III) y Camaleonte de Heraclea (s. IV-III). Y la tercera, por los gramáticos Zenódoto de Éfeso (s. III) primer director de la biblioteca de Alejandría, Aristófanes de Bizancio (s. III-II), Calímaco (s. IV-III), Crates de Tebas? (s. IV-III), Eratóstenes de Cirene (s. III-II), Aristarco de Samos? (s. IV-III) y Apolodoro de Atenas (s. II).

46 Cf. Discurso, 31. 
podido examinar muchas artes e ideas y, por fin, viviendo en Roma, pude contemplar detenidamente la variedad de estatuas por ustedes allí exportadas. ${ }^{47}$

La coincidencia entre el apologista y los griegos es obviamente que en algún momento y por azarosas circunstancias adhirió a la filosofía bárbara, de modo tal que si en el marco de su exposición los griegos son tenidos por ignorantes $(\dot{\alpha} \mu \alpha \theta \varepsilon \hat{\imath} \varsigma)$, él confiesa haber sufrido la misma dolencia. Se hace cargo de una herencia cultural que, a juzgar por sus testimonios, conoce bien, al tiempo que pretende evitar la acusación de haber traído la novedad de la

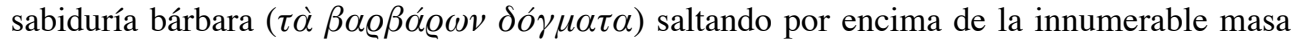

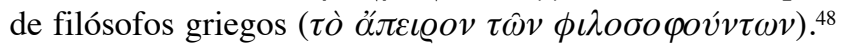

Los "bárbaros" a los que representa, por su parte, no tienen problemas de disenso porque rechazan todo lo que se funda en la mera opinión humana y no dicen mentiras $(\lambda \varepsilon \dot{\varepsilon} \gamma o v v \tau \varepsilon \varsigma$ ov $\psi \varepsilon v \delta o ́ \mu \varepsilon \theta \alpha) ; 49$ Taciano se las arregla, como se ve, para mencionar las ventajas de la "filosofía bárbara" en diferentes partes del proceso de argumentación.

Hasta acá la argumentación de Taciano parece ir contra los historiadores científicos, podría decirse, pero se detiene a armar algunos argumentos de orden moral basados en ejemplos y arquetipos de la Ilíada. Debemos decir que en rigor, es fácil atacar desde otra perspectiva ética y moral la de una cultura que, aunque sus representantes no lo supieran, estaba, a decir de E. R. Dodds, en franca decadencia.

Para dar fin al asunto, en un juego que tiene un ganador anticipado, le da cierta ventaja a los griegos. Toma, pues, la cronología griega más antigua, para alegar, casi como un defensor de los griegos, que se podría conceder que Homero hubiera nacido antes que la invención de los alfabetos, incluso que hubiera combatido en el ejército de Agamenón; pero, sin lugar a dudas, no podría ser considerado anterior a la Guerra de Troya. Así, lo que Taciano busca es probar que, incluso si se toma la cronología más antigua posible desde el punto de vista griego, Moisés es, con todo, más antiguo en muchos años que la toma de Troya, que la misma fundación de Troya, e incluso que Dárdano, el mitológico fundador de la ciudad. Y como testimonio de esta afirmación va a utilizar las cronologías no de los judíos, sino las de los caldeos, de los fenicios y de los egipcios.

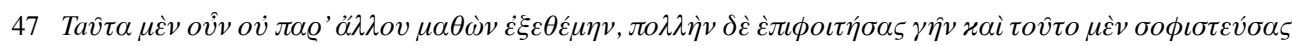

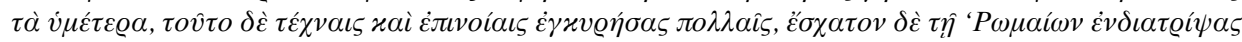

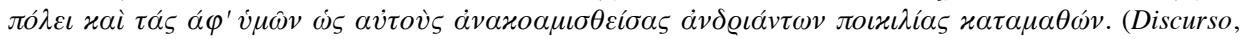
35.1-3)

48 En la transcripción de esta expresión de Taciano, a diferencia de lo que hemos hecho a lo largo de todo el tra-

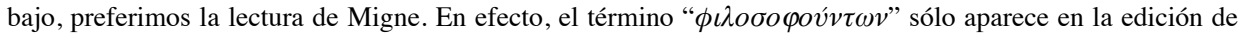

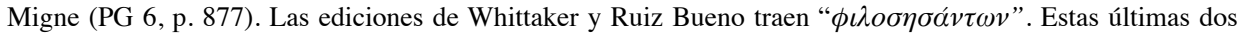
ediciones, con todo, traducen el genitivo plural como "of philosophers" y "de sus filósofos respectivamente". Para más detalles, cf. Tatian (1982), Oratio ad Graecos and fragments (trans. and ed. by Molly Whittaker), Oxford, Clarendon Press, p. 66 y Taciano (1954), Discurso contra los Griegos (trad. y ed. Daniel Ruiz Bueno), en Ruiz Bueno, Daniel, Padres Apologistas Griegos (s. II), Madrid, BAC, p. 621.

49 Cf. Dodds, E. R.(1965), Pagan and Christian in an Age of Anxiety, Londres: Cambridge University Press, passim. 


\subsubsection{Los historiadores bárbaros}

De los caldeos, Taciano toma al historiador Beroso,,$^{50}$ quien vivió en tiempos de Alejandro y escribió una historia de los caldeos en tres libros, dedicada a Antíoco, ${ }^{51}$ tercer sucesor de Alejandro. El rey más antiguo que menciona Beroso es Nabucodonosor, ${ }^{52}$ que - sigueluchó contra fenicios y judíos. Estas campañas de Nabucodonosor fueron anunciadas por los profetas y tuvieron lugar mucho después de la época de Moisés. ${ }^{53}$

Los fenicios, por su parte, tuvieron tres historiadores: Teódoto, Hipsícrates y Mokhos, ${ }^{54}$ cuyos libros, según Taciano, tradujo al griego un tal Leto. Estos autores, en sus historias dejan en claro en qué época sucedió el rapto de Europa y la llegada de Menelao a Fenicia.55 Así como los hechos de Hiram, ${ }^{56}$ con cuya hija se casó Salomón, el rey de los judíos. ${ }^{57}$ Y la época de Hiram se aproxima, remata, a la de Troya. ${ }^{58}$

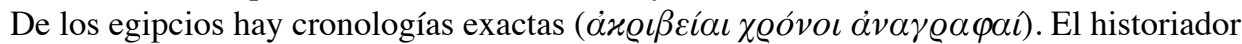
que Taciano menciona como de mayor importancia es Ptolomeo, no el rey sino un sacerdote de Mendes. Según este erudito la salida de los judíos de Egipto habría tenido lugar durante el tiempo del rey Amosis, ${ }^{59}$ y el reinado de Amosis es contemporáneo del reinado de Ínaco; se trata de un testimonio que Taciano afirma que es concordante con los dichos del gramático Apión en su historia egipcia. Ahora bien, Ínaco es el rey de Argos y entre el reinado de Ínaco y la guerra de Troya hay veinte generaciones, i.e., veinte reyes de Argos entre Ínaco y Agamenón: no importan tanto los nombres aquí, ${ }^{60}$ la cuestión es que el reinado de Ínaco pertenece a la historia griega y a partir de éste se puede saber en qué época tuvo lugar la

50 Beroso, conocido hoy como "Beroso el Caldeo" fue un sacerdote de Babilonia que vivió en el s. III a. C. (350270). La información que Taciano tiene de este sacerdote historiador proviene, con cierto grado de probabilidad, de las Antigüedades Judías del historiador Flavio Josefo. Esta afirmación, de la cual somos absolutamente responsables, no es la más corriente entre los estudiosos del historiador judío. De la múltiple y variada bibliografía sobre Flavio Josefo, quizás el artículo más esclarecedor en este sentido es el de la Prof. Sabrina Inowlocki: Inowlocki, S. (2016), «Josephus and Patristic Literature», en Howell Chapman, H.-Rodgers, Z. (eds.), The Blackwell Companion to Josephus, UK: Wiley-Blackwell, esp. pp. 361ss. La profesora Inowlocki afirma en el artículo que el primer autor cristiano que utiliza los textos de Josefo es Teófilo de Antioquía.

51 Se trata de Antíoco I Sóter, de la dinastía de los seléucidas, que reinó entre 281 y 261 a. C.

52 Nabucodonosor habría reinado en Babilonia entre 1125 a. C. y 1103 a. C.

53 Cf. Discurso, 36.

54 Se trata de Mokhos de Sidón, un historiador fenicio del s. XIV a. C, quien habría escrito una obra ya perdida en época de Taciano, con el título de Cosmogonía. Se trata de un autor que, hasta donde es posible afirmarlo con investigaciones actuales, sería anterior a la Guerra de Troya. La figura casi legendaria de Mokhos es mencionada por Estrabón de Ponto y Sexto Empírico; ambos lo consideran el primer pensador atomista.

55 Después del saqueo de Troya, las naves de Menelao se vieron envuelta en una tormenta que los llevó por Libia, fenicia, Chipre y Egipto antes de poder arribar a su patria, Esparta.

56 Se trata de Hiram I, rey de Tiro, que gobernó entre los años 969 y 939 a. C.

57 Cf. 1 R. 5.1-12.

58 Cf. Discurso, 38. En sentido estricto, hoy se considera que la Guerra de Troya ocurrió entre los s. XIII y XII a. C., mientras que Hiram habría vivido unos trescientos años después.

59 Se trata de Amosis I, fundado de la dinastía XVIII del llamado Imperio Nuevo. Su reinado se habría extendido desde el 1550 a. C. hasta el 1525 a. C.

60 Ínaco, Foroneo, Apis, Argivo, Críaso, Forbante, Triopante, Crotopo, Estenelao, Dánao, Linceo, Preto, Abas, Acrisio, Perseo, Estenelao, Euristeo, Atreo, Tiestes, y Agamenón. Troya habría sido tomada en el año dieciocho del reinado de Agamenón. 
Guerra de Troya, por lo que si Moisés fue contemporáneo de Ínaco, es cuatrocientos años más antiguo que la guerra de Troya. De acuerdo con Taciano esto se demuestra no solo por la serie de los reyes áticos sino también por la de los macedonios, los ptolomeos y los antioqueños. Lo cierto es que recién después de Ínaco comenzaron a registrarse los hechos históricos más ilustres de los griegos, es decir, comenzaron a ser registrados en una época posterior a la de Moisés. ${ }^{61}$

Por todo lo dicho, Moisés aparece claramente como más antiguo que todos los héroes, guerras y divinidades de los griegos. Y, por esto, hay que creer al que se aventaja por la edad antes que a los griegos, que fueron a sacar, afirma Taciano, de esta fuente sus enseñanzas sin entenderlas. Muchos de sus "sofistas", con vana curiosidad, trataron de adulterar cuanto conocieron de Moisés y de los que filosofan a la manera de Moisés por dos motivos: para dar la apariencia de decir algo original, y para falsificar la verdad como un conjunto de fábulas, dando un barniz de fingida retórica a lo que habían entendido. ${ }^{62}$

\section{Conclusión}

En el Discurso de Taciano asistimos, pues, al nacimiento de una literatura apologética historiográfica a la que algunos estudiosos han llamado "greco-siria". ${ }^{63}$ Esta literatura discute explícitamente la tradición historiográfica griega, en especial la helenística, y se posiciona frente a ella como la única fundada en la verdad de los hechos. Taciano es el iniciador de este género, en el que también brillará el apologista Teófilo de Antioquía, y sus elementos característicos son los siguientes: 1) la presentación de una cronología universal basada en documentos ( $\dot{\alpha} v \alpha \gamma \varrho \alpha \varphi \alpha i)$ que abraza el período temporal que va desde la Creación hasta el presente del escritor; 2) la discusión explícita con los historiógrafos helenistas que presentaron otras cronologías con características universales; 3 ) la postulación de Moisés como el escritor definitivo de todo argumento historiográfico, es decir, el escritor más antiguo de la humanidad - en esta concepción, Moisés habría narrado todos los procesos de los orígenes y, por tanto, todas las historias, de modo tal que todos los conocimientos de otras tradiciones, en especial de la griega, se deben remitir al texto mosaico como a su origen; 4) a partir de 3) y por razones de obvia conveniencia argumentativa, este género apologético no distingue de manera explícita entre judíos y cristianos; 5) por último, pero no en último lugar, la historiografía que está inaugurando Taciano se soporta en una descalificación a ultranza de todas las tradiciones no judeocristianas que entraña una inconsciencia absoluta de lo que hoy llamamos "relativismo cultural".

61 Taciano cita en su apoyo algunos elementos cuya datación ha sido consignada en los archivos, p.e., batallas, erección de monumentos, etc. cf. Discurso, 38.

62 Cf. Discurso, 40

63 Cf. Scholtz, G (1974), «Geschichte» en Ritter, Joachim-Karldfield, Gründer-Gottfried, Gabriel (eds.), Historisches Wörterbuch der Philosophie, Basel-Stuttgart: Schwabe Verlag, vol. 3, pp. 334-398; Mortley, Raoul (1990), «The Hellenistic Foundations of Ecclesiastical Historiography» en Clark, Greame et al. (ed.), Reading the Past in Late Antiquity, Rushcutters Bay: Australian National University Press, pp. 225-250; Martín, José Pablo (2013), «La historiografía como género apologético en los orígenes cristianos» en Alesso, Marta (ed.): Hermenéutica de los Géneros Literarios: de la Antigüedad al Cristianismo: Buenos Aires, Editorial de la Facultad de Filosofía y Letras (UBA), pp. 87ss. 
Llegados a este punto, es dable tener en cuenta que Taciano escribe en medio de una lucha cultural entre griegos y romanos, a quienes, a juzgar por las acusaciones generales contra su ambigua noción de "filosofía", no parece distinguir con claridad. Ajenos, en principio, al conflicto entre griegos y romanos, los cristianos, y Taciano con ellos, tienen la pretensión de que les ha sido encomendada la llave para entender y llevar a término el camino de la humanidad hacia la salvación. Sólo en tales circunstancias, asumimos, a un cristiano se le podía ocurrir introducir la historiografía en el género apologético.

\section{Referencias Bibliográficas}

El texto griego de Taciano que hemos utilizado y citado en las notas al pie es el de la edición de Molly Whittaker, cuya referencia damos más abajo. No se consigna aquí sólo la bibliografía citada sino también la consultada para la realización de este trabajo.

Bingham, Jeffrey-Jefford, Clayton (eds.) (2016), Intertextuality in the Second Century, Leiden-Boston: Brill.

Dodds, Eric Robertson (1965), Pagan and Christian in an Age of Anxiety, Londres: Cambridge University Press, passim

Edwards, Mark-Goodman, Martin-Price, Simon (eds.) (1999), Apologetics in Roman Empire, Oxford: Oxford University Press.

Elze, Martin (1960), Tatian und seine Theologie, Göttingen: Andenhoeck \& Ruphecht.

Hunt, Emily (2003), Christianity in the Second Century. The case of Tatian, London-New York: Routledge.

Inowlocki, Sabrina (2016), «Josephus and Patristic Literature», en Chapman, H.-Rodgers, Z. (eds.), The Blackwell Companion to Josephus, UK: Wiley-Blackwell, pp. 356-367.

Martín, José Pablo (2013), «La historiografía como género apologético en los orígenes cristianos», en Alesso, M. (ed.): Hermenéutica de los Géneros Literarios: de la Antigüedad al Cristianismo: Buenos Aires, Editorial de la Facultad de Filosofía y Letras (UBA), pp. 63-88.

McGehee, Michael (1993), «Why Tatian never "Apologyzed” to the Greeks», Journal of early Christian Studies, ${ }^{\circ} 1$, pp. 143-155.

Mitchell, Margaret-Young, Frances (eds.) (2008), The Cambridge History of Christianity. Origins to Constantine, Cambridge: Cambridge University Press.

Moreschini, Claudio (2013), Storia del Pensiero Cristiano Tardo-Antico, Milano: Bompiani, 2013.

Moreschini, Claudio (2004), Storia della Filosofia Patristica, Brescia: Editrice Morcelliana, 2004.

Mortley, Raoul (1990), «The Hellenistic Foundations of Ecclesiastical Historiography» en Clark, Greame et al. (ed.), Reading the Past in Late Antiquity, Rushcutters Bay: Australian National University Press, pp. 225-250.

Nasrallah, Laura (2005), «Mapping the World: Justin, Tatian, Lucian, and the Second Sophistic», Harvard Theological Review, $\mathrm{n}^{\circ}$ 98-3, pp. 283-314. 
Norelli, Enrico (1996), «La critique du pluralisme grec dans le Discours aux Grecs de Tatien» en POUDERON, Bernard-DORÉ, Joseph (eds.), Les apologistes chrétiens et la culture grecque, Paris: Beauchesne, pp. 81-120.

Petersen, William (1995), Tatian's Diatesseron. Its creation, dissemination, significance, and history in scholarship, Leiden-New York-Köln: Brill.

Pouderon, Bernard (2005), Les Apologistes grecs du IIe siècle, Paris: Les Éditions du Cerf. Quasten, Johann (1961), Patrología I, Madrid: BAC.

Scholtz, Gunter (1974), «Geschichte» en Ritter, Joachim-Karldfield, Gründer-Gottfried, Gabriel (eds.), Historisches Wörterbuch der Philosophie, Basel-Stuttgart: Schwabe Verlag, vol. 3, pp. 334-398.

Taciano (1954), Discurso contra los Griegos (trad. y ed. Daniel Ruiz Bueno), en Ruiz Bueno, Daniel, Padres Apologistas Griegos (s. II), Madrid, BAC, pp. 572-628.

Tatian (1982), Oratio ad Graecos and fragments (trans. and ed. by Molly Whittaker), Oxford, Clarendon Press.

Tatiani Asyrii (1857), Oratio adversus greacos (trans. and ed. by Jean-Paul Migne), en Migne, Jean-Paul, Patrologiae Graegacea Tomus VI, pp. 803-888.

Young, Frances-Ayres, Lewis-Louth, Andrew (eds.) (2004), The Cambridge History of Early Christian Literature, Cambridge: Cambridge University Press. 